\title{
A Study on the Characteristics of Organic Matter and Nutrients Released from Sediments into Agricultural Reservoirs
}

\author{
Jin-Kyung Lee ${ }^{\mathbb{D}}$ and Jong-Min $\mathrm{Oh}^{*}$ \\ Department of Applied Environmental Science (Environmental Engineering), Kyung-Hee University, \\ Yongin-si 17104, Korea; leejin0508@gmail.com \\ * Correspondence: jmoh@khu.ac.kr; Tel.: +82-(31)-252-4443; Fax: +82-(31)-201-2125
}

Received: 31 May 2018; Accepted: 20 July 2018; Published: 25 July 2018

\begin{abstract}
Most agricultural reservoirs in Korea are more than 50 years old, have low water depth and storage capacity, and have experienced contaminant deposition for decades. Contaminated sedimentation on the reservoir bottom can cause water pollution and eutrophication. Consequently, intervention is required to remove and manage the sediments. We analyzed the release characteristics of organic matter and nutrients from sediments of four reservoirs to predict the pollution caused by sediment release and investigated their effects on water quality. Additionally, the effects of sediment release were compared with those of influent pollutant loads to the reservoirs. We employed the core culture method to determine the release concentrations changes under oxic, anoxic, and control conditions in the collected sediments. In all the studied reservoirs, the release concentrations of nitrate nitrogen increased under oxic conditions and those of ammonia nitrogen, total phosphorus, and phosphate phosphorus increased under anoxic conditions. The water quality was affected by sediment release from the reservoir bottom. The release fluxes (internal sources) of total nitrogen and total phosphorous for the influent pollutant loads (external source) were $2.3-43.7 \%$ and $24.9-48.1 \%$, respectively, for each reservoir. Therefore, optimal pollution control and management strategies will depend on the characteristics of individual reservoirs.
\end{abstract}

Keywords: sediment release characteristics; water pollution; agricultural reservoir; livestock pollution; bottom water

\section{Introduction}

Most of the approximately 17,500 agricultural reservoirs in South Korea are old, with $69.4 \%$ constructed more than 50 years ago and $51.7 \%$ of these even predating 1945 . Furthermore, the water depth in these reservoirs is generally as low as less than $10 \mathrm{~m}$. Inflow and deposition of both point and nonpoint source contaminants have continued for decades, leading to the accumulation of contaminants in the reservoirs. Most reservoirs have continual sediment contamination problems because they are not dredged or the incoming pollution is uncontrolled. Sedimentation of such contaminants at the bottom of agricultural reservoirs can cause water pollution and eutrophication, thus affecting the water quality because of physical and chemical changes [1,2]. Consequently, there is an urgent need to remove and manage such contaminated sediments.

Sediments are repositories for physical and biological debris, and serve as sinks for a wide variety of chemicals [3]. Moreover, a reservoir water column and sediments constitute the basic elements of the aquatic system, forming its benthic habitat. Although contaminated sediments are present in the water column, most pollutants originate from terrestrial sources $[4,5]$. To investigate the migration of sediments flowing through various routes and physical properties in sediments [6], 
several studies of sediment transport mechanics have been conducted on the spatial and temporal migration of sediments [7-10]. Depending on the environmental conditions, sediments can store and discharge nutrients, and therefore play an important role in the circulation of materials in the aquatic environment [11].

After pollutants have been introduced and deposited as sediments, they adversely affect the water quality and aquatic ecosystems as organic matter is decomposed by microorganisms, threatening the survival of the benthos [9,12]. Further, early diagenesis in sediments and the movement of materials between sediments and the water body directly and indirectly affect water quality $[13,14]$. Depending on the environmental conditions of the interface between the sediments and water column, the released nutrients could arise from internal pollution sources containing nitrogen and phosphorus [15]. Therefore, even if the external pollution sources were eliminated, the nitrogen and phosphorus concentrations in the water could remain high [16,17].

Under oxygenic conditions, aerobic microorganisms decompose organic matter using oxygen as an electron acceptor $[18,19]$. Anaerobic metabolism occurs sequentially, resulting from microorganisms that use nitrate, manganese oxide, iron oxide, and sulfate as electron acceptors [1]. In sediments, dissolved inorganic nutrients newly formed by the organic decomposition process accumulate in the pore water, which can gradually be differentiated from the overlying water [20]. As a result, nutrients migrate from the sediments to the water layer by molecular diffusion. In addition, dissolved nutrients can be exchanged between pore water and upper water through various routes such as advection and benthic activity [21].

Most previous studies have examined the changes in nutrient and heavy metal concentrations in the pore water and overlying water of sediments in river or marine systems, and have measured diffusion flux under constant conditions [12,22-24]. However, depending on the source of the influent pollution, the characteristics of the deposited pollutant differ, thus affecting the release of organic matter and nutrients at the sediment-water interface [11]. Therefore, it is important to analyze the release rate depending on the pollution source because it affects the rate and fluxes of release from the sediment to the water layer depending on the movement of deposited organic matter and nutrients [13].

The purpose of this study is to add to the knowledge in this field in the South Korean context by analyzing the effects of sediments on the water quality in agricultural reservoirs after considering the characteristics of the sediments relevant to the year of reservoir construction and type of contaminant source, such as sewage or livestock pollution sources. Since external pollutants are the source of sediment accumulation, the analyzed rate and release fluxes are compared with the influent pollutant loads. Additionally, we studied the effects of water pollution caused by the release of contaminants from sediments according to the physical and chemical changes in the sediments. The results of this study will contribute to the management of sediments and improvement of water quality in the studied agricultural reservoirs according to their respective characteristics. This is the first study to conduct research in this context on these four reservoirs in Korea.

\section{Materials and Methods}

\subsection{Study Area}

Our study area in South Korea comprised four typical agricultural reservoirs known to be contaminated by high concentrations of organic matter. The study sites were selected according to the pollution sources and construction years. While the effective storage capacity (see the note below Table 1 for the definition of this term) of the reservoirs was similar, each reservoir was characterized by different pollution sources and was constructed in a different year. Specifications such as the location, year of construction, and other relevant parameters of each reservoir are shown in Figure 1 and Table 1. Two of the investigated sites were labeled I (constructed before 1960) and E (constructed after 1960), and both types were affected by sewage pollution sources. The other two sites were labeled Y (constructed before 1960) and G (constructed after 1960), and both were affected by livestock 
pollution sources. Furthermore, by analyzing the characteristics of the sediments, we studied their effects on water quality. Field surveys were conducted from April 2015 to November 2016, except during the period December-March, when the water was frozen.

A study conducted by the Rural Research Institute in 2015 [25] to identify the sources of agricultural reservoir pollution in South Korea found the major pollution sources to be livestock $(46.6 \%)$, sewage $(41.4 \%)$, runoff from land $(11.5 \%)$, and others $(0.5 \%)$. Pollution from livestock mainly comprises discharge of animal manure and pesticide application in rural areas. Sewage pollution sources refer to pollutants generated by residents/businesses, and primarily consist of food waste, household waste oil, and sanitary waste discharged from homes and restaurants. Run-off from land contributes to non-point pollution and includes unspecified non-point pollution from cities, roads, farmland, and mountains [26]. This study aimed to analyze two major pollution sources, namely, livestock and residential/commercial, in the four contaminated agricultural reservoirs.

The measured mean water depth at the study sites was less than $5 \mathrm{~m}$, and the basin areas and benefit areas (see the note below Table 1 for the definitions of these terms) were quite similar, except for that of one reservoir (reservoir I).

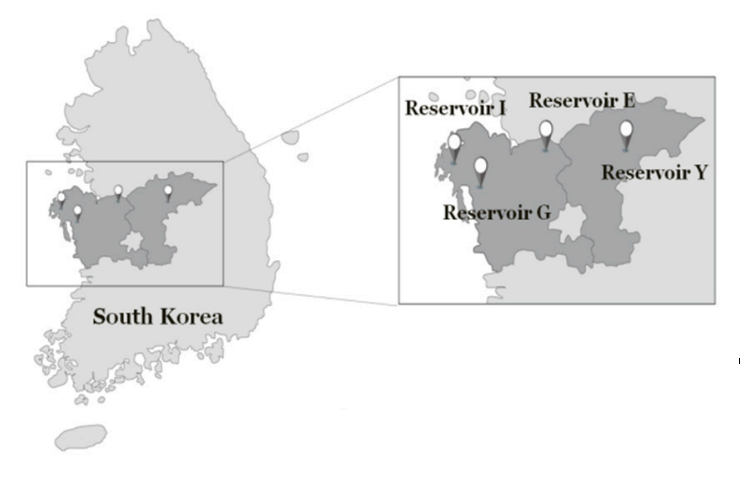

\begin{tabular}{c|c|c}
\hline Reservoir & Latitude & Longitude \\
\hline Reservoir Y & N 36 $86^{\circ} 57.8^{\prime \prime}$ & E $127^{\circ} 87^{\prime} 94.8^{\prime \prime}$ \\
Reservoir G & N 36 $36^{\circ} 49.1^{\prime \prime}$ & E $126^{\circ} 60^{\prime} 05.6^{\prime \prime}$ \\
Reservoir I & N 36 $36^{\circ} 88.0^{\prime \prime}$ & E $126^{\circ} 34^{\prime} 69.0^{\prime \prime}$ \\
Reservoir E & N 36 $36^{\circ} 85.0^{\prime \prime}$ & E $127^{\circ} 13^{\prime} 61.7^{\prime \prime}$ \\
\hline
\end{tabular}

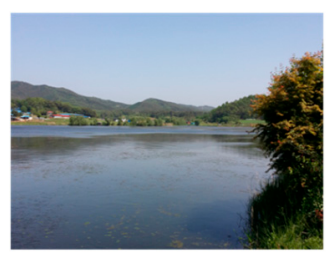

Reservoir $Y$

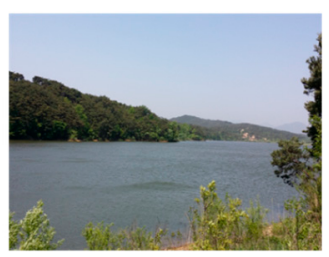

Reservoir G

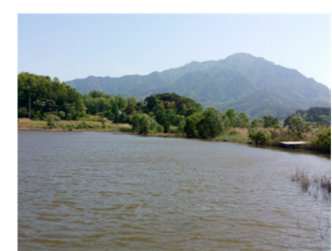

Reservoir I

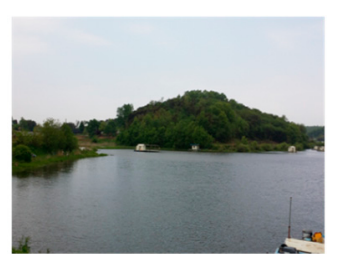

Reservoir E

Figure 1. Sampling sites at reservoirs $Y$, G, I, and E in South Korea.

Table 1. Basic physical properties of the study sites.

\begin{tabular}{|c|c|c|c|c|c|c|c|}
\hline Reservoir & $\begin{array}{l}\text { Pollution } \\
\text { Source }\end{array}$ & $\begin{array}{c}\text { Construction } \\
\text { Year }\end{array}$ & $\begin{array}{c}\text { Basin } \\
\text { Area }^{c} \text { (ha) }\end{array}$ & $\begin{array}{l}\text { Full Water } \\
\text { Area (ha) }\end{array}$ & $\begin{array}{c}\text { Benefit } \\
\text { Area }^{\text {a }} \text { (ha) }\end{array}$ & $\begin{array}{c}\text { Effective Storage } \\
\text { Capacity }{ }^{b}\left(10^{3} \mathrm{~m}^{3}\right)\end{array}$ & $\begin{array}{c}\text { Mean } \\
\text { Depth (m) }\end{array}$ \\
\hline Reservoir Y & Livestock & 1931 & 535.0 & 17.8 & 133.0 & 644 & 2.2 \\
\hline Reservoir G & Livestock & 1985 & 370.0 & 29.6 & 167.5 & 1410 & 4.8 \\
\hline Reservoir I & Sewage & 1938 & 1062.0 & 43.8 & 202.9 & 891 & 2.1 \\
\hline Reservoir E & Sewage & 1972 & 507.0 & 37.4 & 142.0 & 952 & 2.5 \\
\hline
\end{tabular}

Note: Data source-Rural Water Information System (RAWRIS), Korea [27]. ${ }^{\text {a }}$ Benefit area: Areas benefiting from the drainage or irrigation project. ${ }^{b}$ Effective storage capacity: The possible water storage capacity (measured from the lowest water level to the highest water level) available for use. ${ }^{c}$ Basin area: Planar area enclosed by the geographical watershed. 


\subsection{Bottom Water and Sediment Quality}

Sediment sampling at the study sites was performed after considering the depth, location of inflow water, and water pollution conditions. Sampling was conducted more than three times at two to three points exhibiting typical sedimentation characteristics, after which the samples were mixed to obtain one sample. The samples were refrigerated in polyethylene bottles and transported to the laboratory, where the particle size distribution for soil texture, $\mathrm{pH}$, loss on ignition (LOI), total nitrogen (TN), and total phosphorus (TP) were analyzed using the relevant analysis methods for soil and plants [28].

Water sampling was conducted more than three times at two to three points, exhibiting representative water quality of the reservoir bottom. Next, the samples were mixed to obtain one sample. The water depth was collected $0.5 \mathrm{~m}$ above the bottom of each reservoir. Water quality parameters, such as water temperature, $\mathrm{pH}$, electrical conductivity (EC), dissolved oxygen (DO), and $\mathrm{TP}$, at the reservoir bottom were investigated at intervals of three months. In the laboratory, samples were analyzed at $4^{\circ} \mathrm{C}$ or lower, and the results are listed in Table 2 . When water sampling was difficult due to the situation in the field, some of the water quality data from the Agricultural water monitoring reports [26] and Rural Water Information System (RAWRIS) [27] were utilized. The water samples from the reservoirs were analyzed in situ for temperature, $\mathrm{pH}, \mathrm{EC}$, and DO by using a portable meter (Hydrolab DS5: Hach Company, Loverland, CO, USA), and standard methods were followed to analyze the water samples [29]. Chemical oxygen demand $\mathrm{COD}_{(\mathrm{KMnO})}$ obtained the concentrations of organic and oxidizable inorganic substances in the sample oxidized using potassium dichromate in 50\% sulfuric acid solution at the reflux temperature. Suspended solids (SS) were measured by filtering the water sample through a preweighed glass fiber filter (Whatman 1822, GF/C $ø 47 \mathrm{~mm}$ ). Further, TN and TP were analyzed using an automatic water quality analyzer (SYNCA, BRAN + LUEBBE TEC., Norderstedt, Germany). Each measurement was tested for accuracy with a certified reference material, and the recovery was measured to be $90-110 \%$. The water samples were collected carefully to avoid disturbing the sediments. The water depths at all the sites were less than $5 \mathrm{~m}$. The measured DO was $1.3-10.8 \mathrm{mg} / \mathrm{L}$, with water temperature ranging from 4.0 to $29.8^{\circ} \mathrm{C}$ and $\mathrm{pH}$ ranging from 5.8 to 9.3 , depending on the season. This means that anoxic conditions could exist in the reservoirs even at low water depths. The concentration of COD was high at the water surface (not shown here), whereas those of TN and TP were high in the bottom water.

Table 2. Physicochemical characteristics of the bottom water of the study sites.

\begin{tabular}{|c|c|c|c|c|c|c|c|c|c|}
\hline \multicolumn{2}{|c|}{ Reservoir } & $\begin{array}{c}\text { Temperature } \\
\left({ }^{\circ} \mathrm{C}\right)\end{array}$ & $\mathrm{pH}$ & $\begin{array}{c}\text { EC } \\
(\mu S / \mathrm{cm})\end{array}$ & $\begin{array}{c}\mathrm{DO} \\
(\mathrm{mg} / \mathrm{L})\end{array}$ & $\begin{array}{l}\text { COD } \\
(\mathrm{mg} / \mathrm{L})\end{array}$ & $\begin{array}{c}\mathrm{TN} \\
(\mathrm{mg} / \mathrm{L})\end{array}$ & $\begin{array}{c}\mathrm{TP} \\
(\mathrm{mg} / \mathrm{L})\end{array}$ & $\begin{array}{c}\mathrm{SS} \\
(\mathrm{mg} / \mathrm{L})\end{array}$ \\
\hline \multirow{5}{*}{ Y } & Mean & 15.9 & 7.8 & 333 & 5.1 & 15.8 & 1.281 & 0.168 & 32.6 \\
\hline & Median & 17.0 & 7.8 & 333 & 4.6 & 16.3 & 1.317 & 0.171 & 31.6 \\
\hline & Min & 4.0 & 6.2 & 234 & 1.6 & 10.0 & 0.716 & 0.097 & 12.5 \\
\hline & Max & 27.8 & 9.3 & 432 & 8.5 & 21.6 & 1.845 & 0.239 & 52.7 \\
\hline & $\mathrm{SD}$ & 8.2 & 1.4 & 56 & 2.2 & 3.9 & 0.349 & 0.058 & 12.2 \\
\hline \multirow{5}{*}{ G } & Mean & 16.0 & 7.0 & 257 & 4.4 & 15.1 & 2.450 & 0.263 & 45.6 \\
\hline & Median & 17.6 & 7.0 & 258 & 4.8 & 14.6 & 2.652 & 0.277 & 46.0 \\
\hline & Min & 5.2 & 5.8 & 193 & 1.3 & 9.3 & 0.989 & 0.048 & 19.8 \\
\hline & Max & 26.8 & 8.2 & 321 & 7.5 & 20.8 & 3.911 & 0.478 & 71.3 \\
\hline & $\mathrm{SD}$ & 6.7 & 1.0 & 42 & 1.7 & 3.8 & 0.929 & 0.173 & 16.9 \\
\hline \multirow{5}{*}{ I } & Mean & 17.6 & 7.5 & 347 & 6.2 & 16.5 & 1.505 & 0.825 & 59.7 \\
\hline & Median & 18.0 & 7.5 & 346 & 6.0 & 17.4 & 1.504 & 0.806 & 56.5 \\
\hline & Min & 5.4 & 6.3 & 278 & 1.5 & 9.6 & 0.918 & 0.108 & 21.3 \\
\hline & Max & 29.8 & 8.7 & 415 & 10.8 & 23.4 & 2.092 & 1.542 & 98.0 \\
\hline & $\mathrm{SD}$ & 17.3 & 1.2 & 43 & 2.8 & 5.1 & 0.427 & 0.527 & 25.7 \\
\hline \multirow{5}{*}{$\mathrm{E}$} & Mean & 17.3 & 7.5 & 275 & 5.3 & 16.1 & 1.250 & 0.485 & 37.0 \\
\hline & Median & 18.2 & 7.6 & 278 & 4.5 & 16.9 & 1.217 & 0.457 & 38.4 \\
\hline & Min & 5.8 & 6.5 & 204 & 1.4 & 10.2 & 0.804 & 0.112 & 16.0 \\
\hline & Max & 28.7 & 8.5 & 345 & 9.1 & 21.9 & 1.695 & 0.858 & 58.0 \\
\hline & $\mathrm{SD}$ & 7.6 & 1.3 & 45 & 2.3 & 4.0 & 0.317 & 0.240 & 11.8 \\
\hline
\end{tabular}


The physical and chemical properties of the sediments from the study sites are presented in Table 3. The soil textures of the sediments from all study sites showed similar characteristics (namely, Silty Clay Loam or SiCL). The texture classes are typically displayed in what is known as the United States Department of Agriculture (USDA) texture triangle [30]. Our analysis showed that the fraction of fine particles below $63 \mu \mathrm{m}$ was greater than $70 \%$. After precipitation of the organic matter, the sediment surface layer is expected to show texture characteristics similar to that of soil formed by oxidation and deposition processes. The results of previous studies indicate that the nutrients released from sediments into the overlying water correlate highly with the particle size of the sediments, and that the higher the fine particle content (e.g., clay), the greater the release of nutrients. This is because phosphorus is adsorbed weakly onto the surface of fine particles such as clay and can therefore move easily into the water because of the weak binding force [31].

Table 3. Physical and chemical characteristics of sediments from the study sites.

\begin{tabular}{|c|c|c|c|c|c|c|c|c|}
\hline \multirow{2}{*}{ Reservoir } & \multirow{2}{*}{$\begin{array}{c}\text { Soil } \\
\text { Texture }\end{array}$} & \multicolumn{3}{|c|}{ Particle Size Distribution (\%) } & \multirow{2}{*}{$\mathrm{pH}$} & \multirow{2}{*}{$\begin{array}{l}\text { LOI } \\
(\%)\end{array}$} & \multirow{2}{*}{$\begin{array}{c}\text { TN } \\
(\mathrm{mg} / \mathrm{kg})\end{array}$} & \multirow{2}{*}{$\begin{array}{c}\text { TP } \\
(\mathrm{mg} / \mathrm{kg})\end{array}$} \\
\hline & & Sand & Silt & Clay & & & & \\
\hline Reservoir Y & $\mathrm{SiCL}^{*}$ & 1.6 & 67.4 & 31.0 & 6.3 & 13.4 & 7157 & 1720 \\
\hline Reservoir G & $\mathrm{SiCL}$ & 7.4 & 61.6 & 31.0 & 5.2 & 12.8 & 5625 & 1684 \\
\hline Reservoir I & $\mathrm{SiCL}$ & 2.7 & 63.3 & 34.0 & 6.2 & 9.4 & 3094 & 1743 \\
\hline Reservoir E & $\mathrm{SiCL}$ & 4.2 & 65.8 & 30.0 & 5.4 & 9.0 & 2505 & 1123 \\
\hline
\end{tabular}

LOI and TN in sediments of reservoirs $Y$ and G, which are affected by livestock pollution, were higher than the corresponding values for reservoirs I and E, which are affected by sewage pollution. TP, on the other hand, was not significantly affected by the type of reservoir pollution source. Further investigation is thus required for an accurate correlation analysis. Furthermore, the older reservoirs (Y and I) typically showed high pollution levels for each analyzed parameter.

\subsection{Sediment Release Analysis}

Various environmental conditions and factors affect the release of organic matter and nutrients at the sediment-water interface. Physical, chemical, and biological processes, such as the composition of sediments, oxygen concentration in the water, oxidation-reduction state of sediments, water temperature, sediment temperature, amount and quality of deposited organic matter, community structure of benthic organisms, and water depth, are involved in the migration of organic matter and nutrients between the sediments and water column. In the current study, release analysis was conducted using the core culture method, which is easier than conducting field measurements and can be tested relevant to the conditions in the laboratory. The core culture method allows one to control and study different environmental conditions and therefore has been used in various studies. The use of this experimental method in migration studies on sediments in low water depth conditions has been reported to return reliable results comparable to field measurements [32,33].

In this study, we used the laboratory core incubation technique, that is, culturing sediments for a certain time period, to measure the concentration change over time, and the results were applied toward further calculations. This method facilitates the measurement of concentration changes in dissolved matter in surface sediments of a certain area and in water column of a certain volume over time. It also allows the calculation of concentration changes in matter deposited on the sediments or released from them. The reservoir samples for the release analysis were sampled in April, and not for the agricultural water supply period, for the stable sampling in the field; the experiment was conducted twice to reduce the error of the sediment experiment procedure. An acrylic reactor was constructed for the release analysis of the reservoir (field) water (Figure 2). To prevent air inflow from the atmosphere, a rubber plate and an acrylic cover were used to seal the upper part of the reactor. The reactor lid consists of an inlet for air and nitrogen, as well as an inlet to measure dissolved oxygen and water 
temperature in real time to match experimental conditions. The reactor was shaded to control oxygen production by algae photosynthesis and to observe only those concentration changes due to the inherent deposition of sediments. The experiments were performed under oxic and anoxic conditions, and a control test was used to measure concentration changes in field water without changing any other conditions. Table 4 shows each experimental condition for the release rate analysis. Before the release analysis, the site sediment samples were stabilized by pre-incubation for three to five days. This process allows the microorganisms in the sediments to adapt to the experimental conditions before the experiment commences, reverting them to a state similar to that at the original site. The reactor was maintained at room temperature $\left(20-25^{\circ} \mathrm{C}\right)$ and the DO concentration was maintained at $5-7 \mathrm{mg} / \mathrm{L}$ for the oxic condition. Anoxic conditions were achieved by continuous injection of nitrogen gas after sealing to prevent the entry of oxygen into the reactor. Changes in the concentration of DO play an important role in the release characteristics of nutrients as they modify the oxidation-reduction conditions in the water [18]. Therefore, this experiment was performed by observing changes in the DO concentration. The supernatant sample was collected immediately after stabilization (day 0 ), after which oxygen and nitrogen gases were injected, and $10 \mathrm{~mL}$ of the supernatant sample was collected on days $1,2,3,4,6,8,10$, and 12 . This sample was filtered with a $0.45-\mu \mathrm{m}$ filter syringe and refrigerated at $4{ }^{\circ} \mathrm{C}$ until analysis.

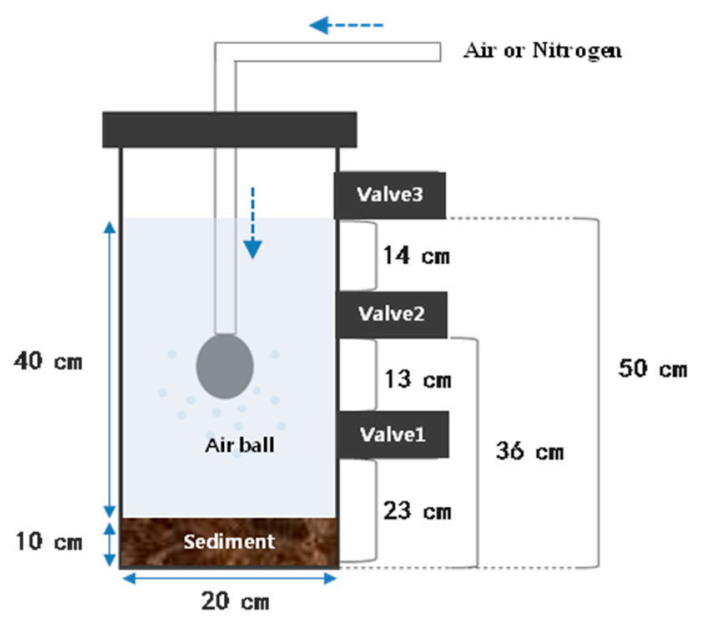

Figure 2. Schematic of the reactor used for sediment release analysis.

Table 4. Experimental conditions for release rate analysis.

\begin{tabular}{cccccc}
\hline Reservoir & Condition & Temperature $\left({ }^{\circ} \mathbf{C}\right)$ & EC $(\mu \mathbf{S} / \mathbf{c m})$ & DO $(\mathbf{m g} / \mathbf{L})$ & pH \\
\hline \multirow{3}{*}{ Reservoir $Y$} & Control & 24.0 & 294 & 3.1 & 7.1 \\
& Oxic & 23.9 & 258 & 6.8 & 7.6 \\
& Anoxic & 22.6 & 261 & 2.2 & 8.7 \\
\hline \multirow{3}{*}{ Reservoir G } & Control & 24.2 & 247 & 3.3 & 7.6 \\
& Oxic & 24.0 & 233 & 6.6 & 7.8 \\
& Anoxic & 22.5 & 230 & 2.2 & 9.1 \\
\hline \multirow{3}{*}{ Reservoir I } & Control & 25.1 & 379 & 3.2 & 7.5 \\
& Oxic & 25.0 & 353 & 5.9 & 7.9 \\
& Anoxic & 23.9 & 345 & 2.1 & 9.1 \\
\hline \multirow{3}{*}{ Reservoir E } & Control & 25.1 & 245 & 3.1 & 7.3 \\
& Oxic & 24.8 & 238 & 6.1 & 8.0 \\
& Anoxic & 23.7 & 228 & 1.9 & 8.8 \\
\hline
\end{tabular}

The supernatant samples were analyzed for TN and TP using an automatic water quality analyzer (SYNCA, BRAN + LUEBBE TEC., Norderstedt, Germany). Ammonia nitrogen $\left(\mathrm{NH}_{4}-\mathrm{N}\right)$, 
nitrate nitrogen $\left(\mathrm{NO}_{3}-\mathrm{N}\right)$, and phosphate phosphorus $\left(\mathrm{PO}_{4}-\mathrm{P}\right)$ were analyzed using an automatic nutrient analyzer (AACS5, BRAN + LUEBBE TEC., Norderstedt, Germany). Each measurement was tested for accuracy with a certified reference material and the recovery was measured to be $90-110 \%$. The release rate was quantified by analyzing the variation in the supernatant concentration according to the elapsed time $(T)$ based on Fick's law. The concentrations of organic matter and nutrients on the sediment surface of a certain area $(A)$ were analyzed and the supernatant of a certain volume was measured at $T$. The release rate of the sediments was calculated as follows:

$$
\text { Release rate }\left(\frac{\mathrm{g} \mathrm{N} \text { or } \mathrm{P}}{\mathrm{m}^{2} \times \mathrm{d}}\right)=\left(\frac{\left(C_{a}-C_{i}\right) \times V}{T \times A}\right)
$$

where $C_{i}$ is the initial concentration of the organic matter and nutrients $\left(\mathrm{g} \mathrm{N}\right.$ or P/L); $C_{a}$ denotes the subsequent concentrations of the organic matter and nutrients $(\mathrm{g} \mathrm{N}$ or $\mathrm{P} / \mathrm{L}) ; V$ is the capacity of the reactor $(\mathrm{L}) ; T$ is the time $(\mathrm{d})$; and $A$ is the area of the reactor $\left(\mathrm{m}^{2}\right)$.

\section{Results and Discussion}

We analyzed the concentration variations of organic matter and nutrients in the supernatant during our sediment core culture experiments. The release analysis conditions of the supernatant are shown in Table 4. The release rates of organic matter and nutrients from sediments from the four study sites were analyzed according to the following factors: year of construction, pollution source, and environmental conditions. Furthermore, the release characteristics of the sediments were compared with the pollutant loads to the reservoir and analyzed to determine their influence rate.

\subsection{Concentration Variations in Organic Matter and Nutrients in the Study Area}

The results of the release analysis showed that the $\mathrm{NO}_{3}-\mathrm{N}$ concentration increased and the $\mathrm{NH}_{4}-\mathrm{N}$ concentration decreased under oxic conditions in all the studied reservoirs. Furthermore, the concentrations of $\mathrm{NH}_{4}-\mathrm{N}, \mathrm{TP}$, and $\mathrm{PO}_{4}-\mathrm{P}$ increased over time in the supernatant of all the samples under anoxic conditions, and the release results for the control sample differed for the analyzed characteristics for each study site.

The variations in the concentrations of organic matter and nutrients, with the release time, are shown in Figure 3 (Y reservoir) and Figure 4 (I reservoir). Reservoir Y, which received livestock pollution loads, showed a decrease in COD concentration under oxic conditions over time. This is because easily decomposable organic matter is deposited on the sediments. As the oxygen supply increases, the aerobic microorganisms decompose the organic matter using oxygen as an electron acceptor; however, the organic matter concentration is reduced by molecular diffusion in the water. In contrast, the COD concentrations were not significantly reduced under oxic conditions in the other reservoirs. No specific variation with changes in conditions was detected in the release results for TN.

However, the concentration change was remarkable during the initial five days of the release analysis, after which it remained stable, with little change under oxic and anoxic conditions at all sites. The concentration of $\mathrm{NH}_{4}-\mathrm{N}$ increased gradually and decreased after six days in the control. Additionally, $\mathrm{NH}_{4}-\mathrm{N}$ showed clearly opposite trends, with an increase in concentrations under anoxic conditions and a decrease under oxic conditions. It appears that the concentration of $\mathrm{NH}_{4}-\mathrm{N}$ increased because of the inhibition of nitrification under anoxic conditions. We consider $\mathrm{NH}_{4}-\mathrm{N}$ to have been released from the sediments into the supernatant by diffusion, with the decomposition of the organic matter on the sediments because of the concentration gradient in the diffusion boundary layer.

Conversely, the concentration of $\mathrm{NO}_{3}-\mathrm{N}$ was higher under oxic conditions. This is because $\mathrm{NH}_{4}-\mathrm{N}$ in the pore water was nitrified actively to $\mathrm{NO}_{3}-\mathrm{N}$ by continuous oxygen supply, and the diffusion release of $\mathrm{NH}_{4}-\mathrm{N}$ was suppressed. Under oxic conditions, $\mathrm{NH}_{4}-\mathrm{N}$ flowed from the water into the sediments, and $\mathrm{NO}_{3}-\mathrm{N}$ flowed from the sediments into the water. In this manner, depending on the concentration of oxygen in the water, the organic matter and nutrients in the sediments were affected by chemical reactions and the chemical composition was determined, thereby altering the material 
exchange process between the sediments and water. We conclude that ammonification, nitrification, and denitrification selectively proceeded depending on the environmental conditions indicated by the DO concentrations, which affected the variations in concentrations of the organic matter and nutrients in the supernatant.

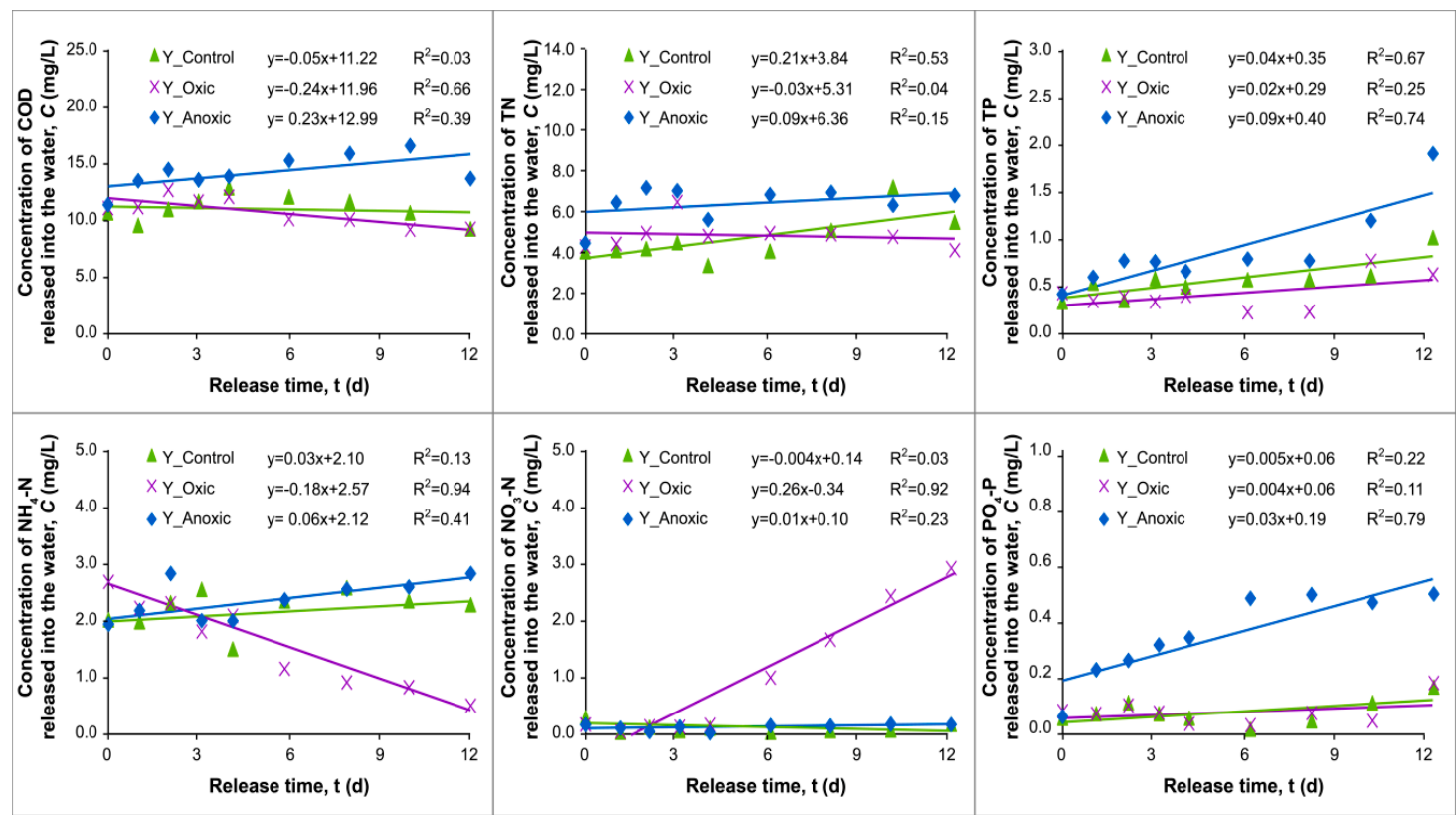

Figure 3. Variations in concentrations of organic matter and nutrients with release time (for reservoir $\mathrm{Y}$ ).

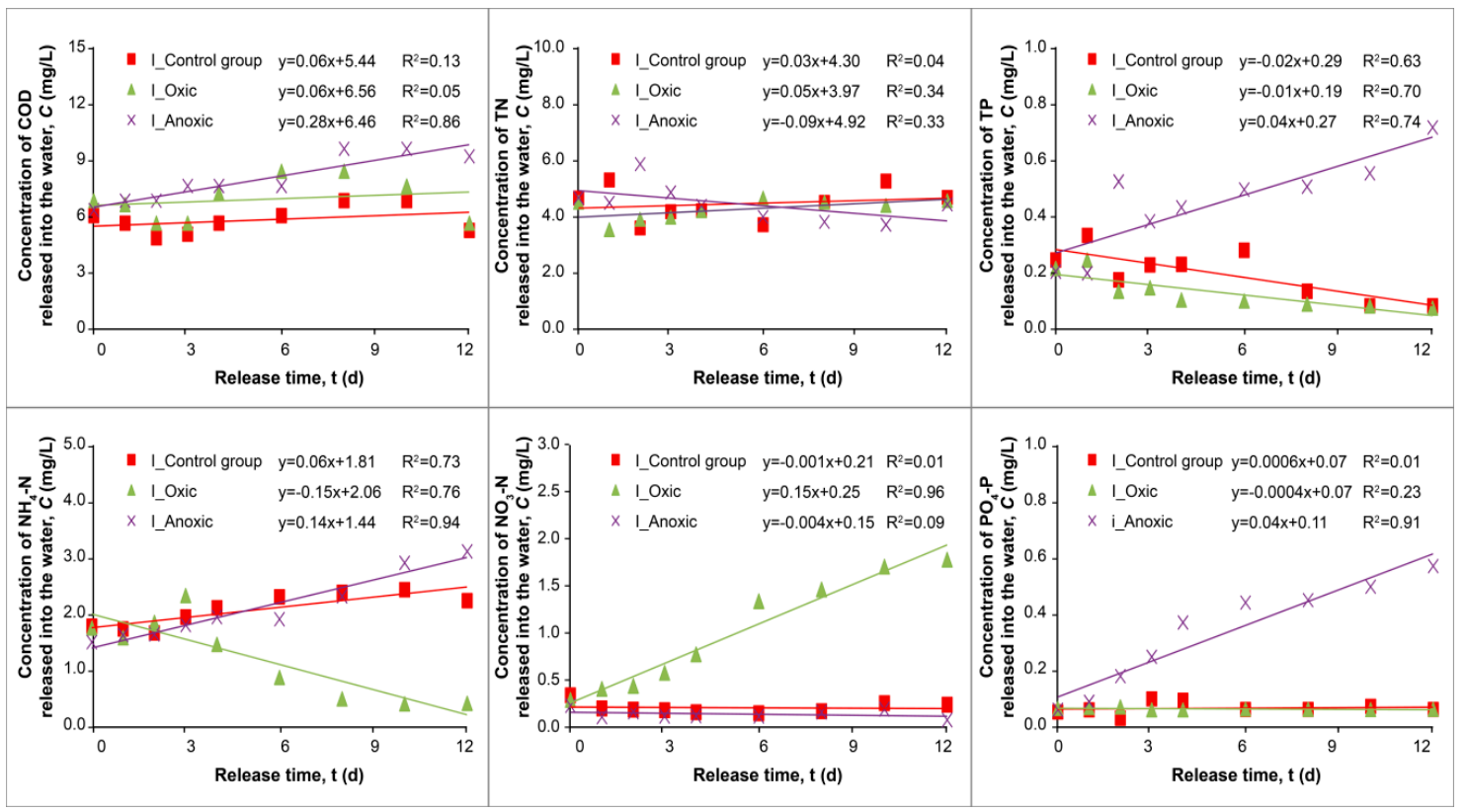

Figure 4. Variations in concentrations of organic matter and nutrients with release time (for reservoir I).

TP and $\mathrm{PO}_{4}-\mathrm{P}$ showed a gradual increase in the control but little change under oxic conditions. On the other hand, they showed a tendency to increase remarkably under anoxic conditions because of the accelerated release of phosphorus by biogeochemical reactions in the supernatant and pore water with variations in the DO concentration. Phosphorus is known to adsorb on iron oxide $\left(\mathrm{Fe}^{3+}\right)$ in the oxidation environment and dissociate from iron oxide $\left(\mathrm{Fe}^{3+}\right)$ in the reduction environment, after which it exists in ionic form with $\mathrm{Fe}^{2+}$ in the pore water [14]. The release of phosphorus from sediments 
was significantly influenced by the oxidation-reduction environment of the diffusion boundary layer between the sediments and supernatant. Moreover, the distribution of the chemical species in the water and sediments varied with the oxygen concentration in the water. Our results are comparable with the findings of other studies [34,35].

$\mathrm{DO}$ had a significant effect on phosphorus because of the changes in $\mathrm{pH}$ or the redox potential. In this study, measured $\mathrm{pH}$ was approximately 7-9, showing no substantial change under oxic and anoxic conditions during the experimental period. These results indicate that the release of phosphorus accelerated under anoxic conditions because of the low redox potential and reducing state. Whereas the change in the concentration of TN was small, the increase in the concentration of phosphorus was remarkable. These results indicate that phosphorus concentrations caused by sediment release should continue to be monitored.

The variations in the concentrations of organic matter and nutrients of reservoir I, which received pollutant loads from sewage sources, were similar to those of reservoir $\mathrm{Y}$. Except for $\mathrm{NO}_{3}-\mathrm{N}$, the concentrations of $\mathrm{NH}_{4}-\mathrm{N}, \mathrm{TP}$, and $\mathrm{PO}_{4}-\mathrm{P}$ increased significantly under anoxic conditions. On the other hand, under oxic conditions, the concentration of $\mathrm{NO}_{3}-\mathrm{N}$ increased significantly, and those of $\mathrm{NH}_{4}-\mathrm{N}$ and TP tended to decrease continuously. This is similar to the observations noted for reservoir $\mathrm{Y}$, where nitrification was suppressed under anoxic conditions and ammonification of microorganisms was accelerated, leading to the release of $\mathrm{NH}_{4}-\mathrm{N}$ from the sediments into the supernatant. Additionally, $\mathrm{NH}_{4}-\mathrm{N}$ changed into $\mathrm{NO}_{3}-\mathrm{N}$ because nitrification was accelerated under oxic conditions, the phosphorus complex combined with the organic matter, and metal oxide was deposited on the sediments. However, a difference was detected in the tendency of the concentration change for the controls between reservoir I (reservoir E), which received pollutant loads from sewage sources, and reservoir Y (reservoir G), which received pollutant loads from livestock pollution sources. For the control group of reservoir I, TN and TP showed little or no decrease in concentration, whereas in reservoir Y (which experienced livestock pollution loads), TN and TP showed the tendency to increase continuously. Under anoxic conditions, $\mathrm{NH}_{4}-\mathrm{N}$ increased continuously in reservoir I over time, whereas in reservoir $Y$, although its initial concentration increased, the increase was insignificant.

Under anoxic conditions, the rate of ammonification differed depending on the pollution source, and the initial release concentration increased greatly, likely in accordance with the components of animal manure and feed. However, ammonification progressed slowly over time because of the decomposition. We thus deduced that the nitrogen in livestock manure was responsible for the difference in the decomposition and binding force compared with that in sewage generated from sewage sources. With regard to phosphorus, reservoir I showed a significant increase under anoxic conditions and reservoir $Y$ showed a marked decrease under oxic conditions. These results suggest that the COD and phosphorus concentrations increased under anoxic conditions because phosphorus combined with the organic matter released from the sediments and diffused into the supernatant.

The spatial and temporal distribution maps for all four reservoirs are shown in Figure 5 so as to facilitate comprehension of Figures 3 and 4. The maps for TP were prepared for the concentrations that show the most prominent release under anoxic conditions. This presentation can confirm the magnitude of the change in the release concentration over time in the reservoir. Figure 5 shows that the variation in the TP release concentration of reservoirs $Y$ and $G$, which experienced livestock pollution, was the largest, and the release concentration was measured to be four times higher than the initial concentration after 12 days. This result suggests that dissolution of TP may occur when anoxic conditions last over several days. 

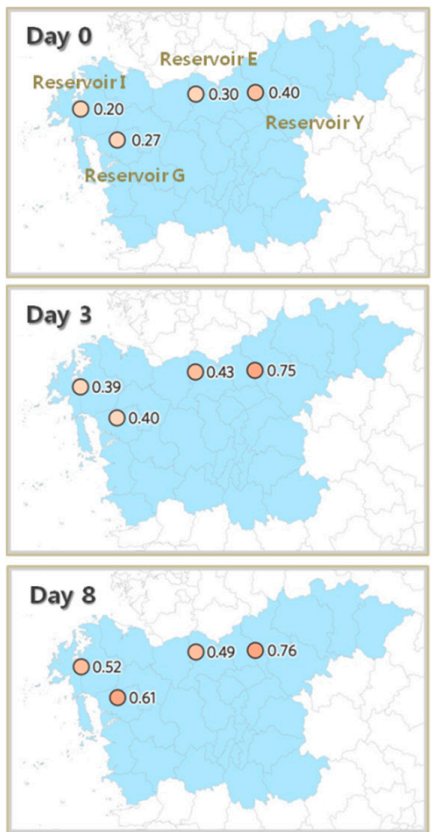
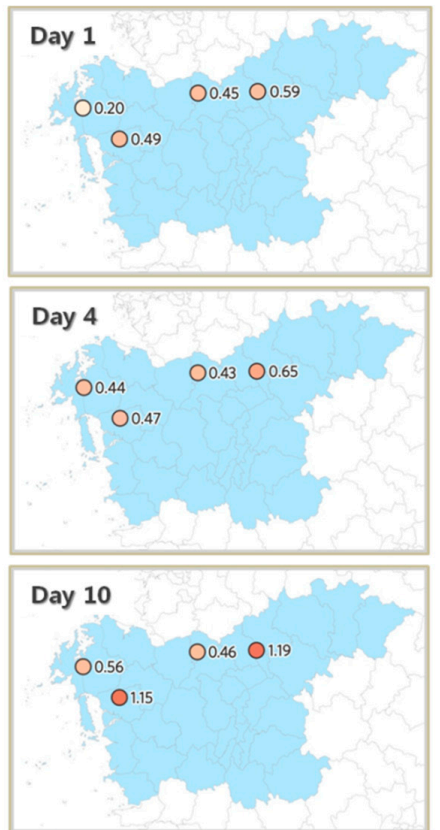
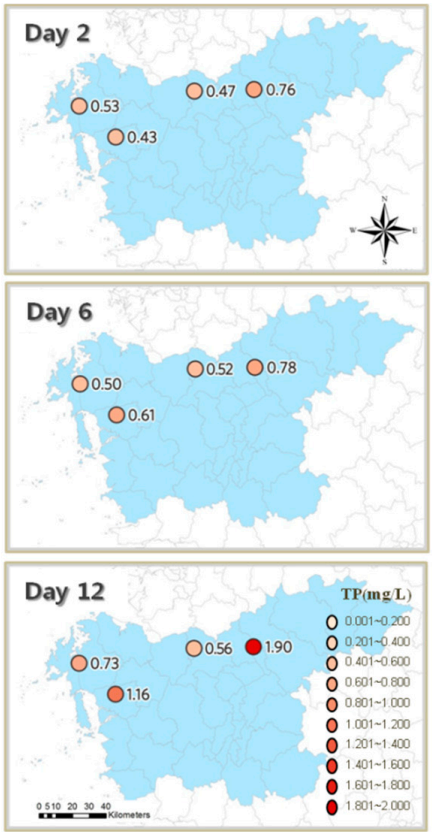

Figure 5. Spatial and temporal distribution maps of the changes in concentration of total phosphorus (TP) under anoxic conditions.

\subsection{Comparison of Release Rates in the Study Area}

The release rates of organic matter and nutrients for the four study sites are shown in Figure 6 and summarized in Table 5 according to the experimental conditions. These release rates varied according to the pollution source, year of construction, and experimental environmental conditions (control, oxic, or anoxic). The following factors were included in the analyses of the release rates: COD (-138.3-347.3 $\mathrm{mg} / \mathrm{m}^{2}$.day), TN $\left(-75.9-301.2 \mathrm{mg} / \mathrm{m}^{2}\right.$.day), TP $\left(-14.6-42.4 \mathrm{mg} / \mathrm{m}^{2} \cdot\right.$ day $), \mathrm{NH}_{4}-\mathrm{N}$ $\left(-97.2-51.1 \mathrm{mg} / \mathrm{m}^{2}\right.$.day), $\mathrm{NO}_{3}-\mathrm{N}\left(-29.3-51.7 \mathrm{mg} / \mathrm{m}^{2} \cdot\right.$ day $)$, and $\mathrm{PO}_{4}-\mathrm{P}\left(-0.9-31.0 \mathrm{mg} / \mathrm{m}^{2} \cdot\right.$ day $)$. The analyses showed that $\mathrm{COD}, \mathrm{TN}, \mathrm{TP}, \mathrm{NH}_{4}-\mathrm{N}$, and $\mathrm{PO}_{4}-\mathrm{P}$ had high release rates under anoxic conditions and exhibited relatively little or no release under oxic conditions. This result is ascribed to the release of organic matter, nutrients being reduced or suppressed as oxidation proceeds, and nitrification caused by an excess of DO under oxic conditions.

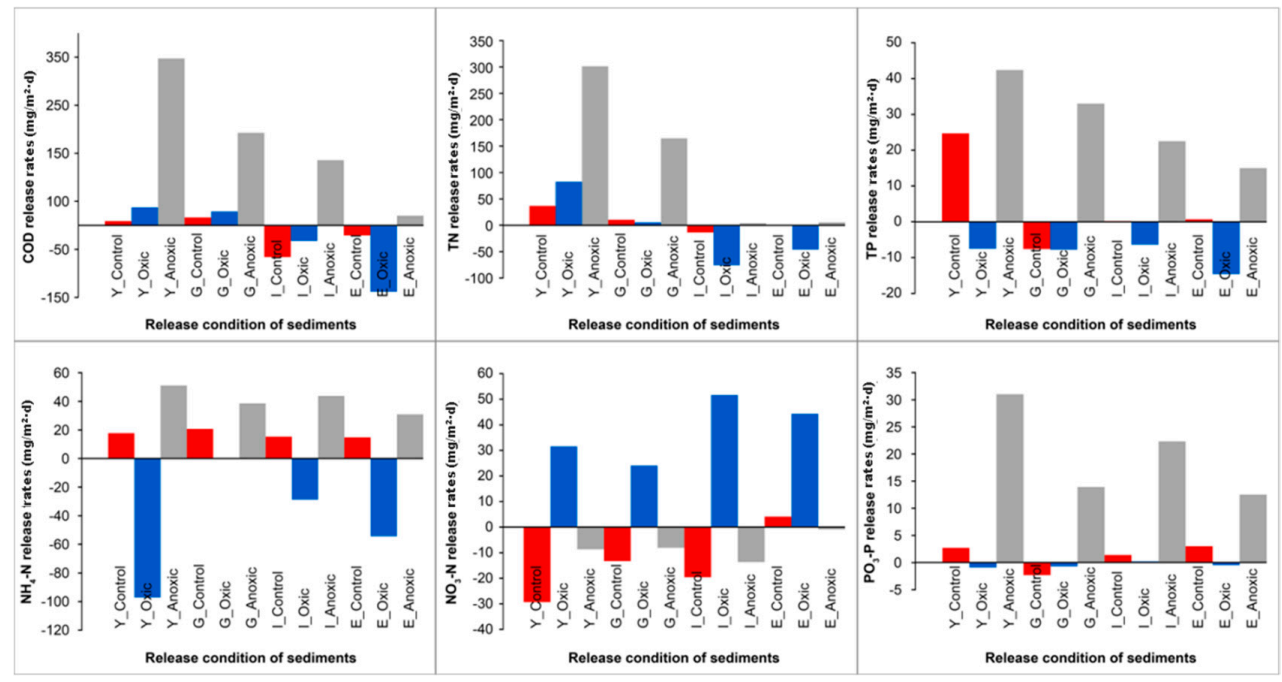

Figure 6. Release rates based on the release condition of sediments. 
Conversely, $\mathrm{NO}_{3}-\mathrm{N}$ had a high release rate under oxic conditions. As nitrification progressed, $\mathrm{NH}_{4}-\mathrm{N}$ release was inhibited, and it did not diffuse into the water. $\mathrm{TN}$ tended to be released under oxic conditions in reservoir $Y$, which experienced pollutant loads from a livestock pollution source and is an old reservoir. These results suggest that the release rates of organic nitrogen and $\mathrm{NO}_{3}-\mathrm{N}$ increased as nitrification progressed under oxic conditions, and this value depends on the characteristics of livestock pollutants such as manure and wastewater.

Table 5. Summary of benthic release rates of sediments.

\begin{tabular}{|c|c|c|c|c|c|c|c|c|c|}
\hline \multirow{2}{*}{ Site } & \multirow{2}{*}{ Construction Year } & \multirow{2}{*}{ Pollution Source } & \multirow{2}{*}{ Condition } & \multicolumn{6}{|c|}{ Release Rates $\left(\mathrm{mg} / \mathrm{m}^{2} \cdot\right.$ Day $)$} \\
\hline & & & & COD & TN & TP & $\mathrm{NH}_{4}-\mathrm{N}$ & $\mathrm{NO}_{3}-\mathrm{N}$ & $\mathrm{PO}_{4}-\mathrm{P}$ \\
\hline \multirow{3}{*}{ Reservoir Y } & \multirow{3}{*}{1931} & \multirow{3}{*}{ Livestock } & Control & 8.8 & 36.6 & 24.7 & 17.7 & -29.3 & 2.7 \\
\hline & & & Oxic & 37.5 & 82.7 & -7.5 & -97.2 & 31.6 & -0.9 \\
\hline & & & Anoxic & 347.3 & 301.2 & 42.4 & 51.1 & -8.7 & 31.0 \\
\hline \multirow{3}{*}{ Reservoir G } & \multirow{3}{*}{1985} & \multirow{3}{*}{ Livestock } & Control & 16.6 & 10.3 & -7.6 & 20.7 & -13.3 & -2.3 \\
\hline & & & Oxic & 29.0 & 5.7 & -7.8 & -0.3 & 24.1 & -0.7 \\
\hline & & & Anoxic & 192.6 & 164.8 & 33.0 & 38.6 & -8.1 & 13.9 \\
\hline \multirow{3}{*}{ Reservoir I } & \multirow{3}{*}{1938} & \multirow{3}{*}{ Sewage } & Control & -66.0 & -13.7 & 0.2 & 15.3 & -19.6 & 1.4 \\
\hline & & & Oxic & -32.7 & -75.9 & -6.4 & -28.8 & 51.7 & 0.2 \\
\hline & & & Anoxic & 135.5 & 4.0 & 22.5 & 43.8 & -13.7 & 22.3 \\
\hline \multirow{3}{*}{ Reservoir E } & \multirow{3}{*}{1972} & \multirow{3}{*}{ Sewage } & Control & -21.0 & 0.2 & 0.7 & 14.8 & 4.1 & 3.0 \\
\hline & & & Oxic & -138.3 & -46.1 & -14.6 & -54.4 & 44.3 & -0.5 \\
\hline & & & Anoxic & 20.2 & 5.4 & 15.0 & 30.9 & -0.9 & 12.5 \\
\hline
\end{tabular}

Statistical analysis of the comparison of release rates under the oxic and anoxic conditions was performed based on the construction year and pollution source type. The groups were divided according to the construction year before and after 1960. A T-test was performed using the statistical program SPSS 20.0 (Statistical Package for the Social Sciences) (Table 6). In addition, a T-test was performed for the divisions of sewage and livestock pollutions (Table 7). A null hypothesis $\left(H_{0}: \mu_{A}=\mu_{B}\right)$ was used to test that "the release rate of between groups is not different at a statistically significant level ( $\alpha=0.05)$." The verification based on the construction year showed statistically significant difference in the $\mathrm{PO}_{4}-\mathrm{P}$ release value $(p<0.05)$ under anoxic conditions (Table 6). Moreover, the verification based on the pollution source type showed statistically significant differences in COD, TN, and TP release values $(p<0.05$; Table 7$)$. In other words, in the divisions based on construction years and pollution source types, it was confirmed that there may be differences in the significance level according to the items under the anaerobic conditions. $\mathrm{NH}_{4}-\mathrm{N}$ does not follow the normal distribution and is excluded from Tables 6 and 7.

Depending on the type of pollution source, the release rates in the old reservoirs were high for each pollution source. Except for the release rate of $\mathrm{TN}$ from sewage pollution sources, all the results showed positive release rates under anoxic conditions, which were particularly pronounced for COD, $\mathrm{TN}, \mathrm{TP}, \mathrm{NH}_{4}-\mathrm{N}$, and $\mathrm{PO}_{4}-\mathrm{P}$. However, $\mathrm{NO}_{3}-\mathrm{N}$ showed a positive release rate under oxic conditions, with a higher rate in the old reservoirs despite the pollution source.

Regarding the release rate for each pollution source according to the reservoir construction year, the organic pollutant release rate was higher from the livestock pollution source than the sewage pollution source under anoxic conditions. However, $\mathrm{NO}_{3}-\mathrm{N}$ showed a higher release rate for the latter pollution source under oxic conditions. This finding can be ascribed to the denitrification effect of nitrite and nitrate and to the biological activity in the sediments.

The release rates of organic matter and nutrients were high in the old reservoirs and more prominent in the reservoirs affected by livestock pollution. Furthermore, the positive or negative release rates had similar characteristics depending on the type of pollution source rather than the construction year, as shown in Figure 6. We therefore deduced that the effect of water pollution on the reservoir owing to sediment release under anoxic conditions was greater than that under oxic conditions. 
Table 6. Statistical result of sediment release rates based on the construction years (constructed before and after 1960) under oxic or anoxic conditions.

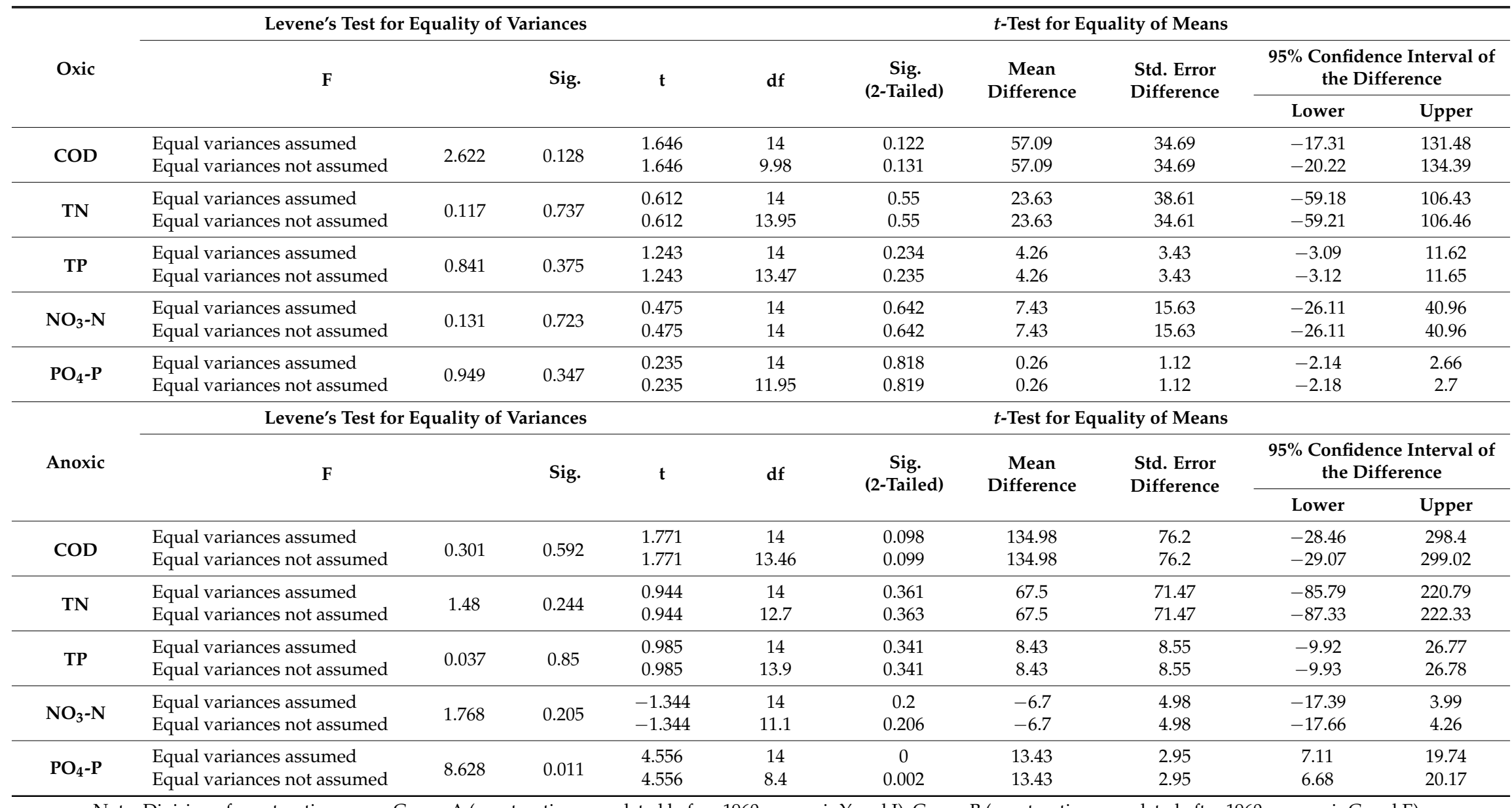

Note: Division of construction years: Group A (construction completed before 1960 reservoir Y and I); Group B (construction completed after 1960: reservoir G and E). 
Table 7. Statistical result of release rates from sediments on the division of pollution source types under oxic or anoxic conditions.

\begin{tabular}{|c|c|c|c|c|c|c|c|c|c|c|}
\hline & \multirow{3}{*}{ Oxic } & \multicolumn{4}{|c|}{ Levene's Test for Equality of Variances } & \multicolumn{5}{|c|}{$t$-Test for Equality of Means } \\
\hline & & \multirow[t]{2}{*}{$\mathbf{F}$} & \multirow[t]{2}{*}{ Sig. } & \multirow[t]{2}{*}{$\mathrm{t}$} & \multirow[t]{2}{*}{$\mathrm{df}$} & \multirow{2}{*}{$\begin{array}{l}\text { Sig. } \\
\text { (2-Tailed) }\end{array}$} & \multirow{2}{*}{$\begin{array}{c}\text { Mean } \\
\text { Difference }\end{array}$} & \multirow{2}{*}{$\begin{array}{l}\text { Std. Error } \\
\text { Difference }\end{array}$} & \multicolumn{2}{|c|}{$\begin{array}{c}95 \% \text { Confidence Interval of } \\
\text { the Difference }\end{array}$} \\
\hline & & & & & & & & & Lower & Upper \\
\hline \multirow{2}{*}{ COD } & Equal variances assumed & \multirow{2}{*}{1.02} & \multirow[b]{2}{*}{0.33} & 2.31 & 14 & 0.057 & 118.73 & 51.39 & 8.51 & 228.94 \\
\hline & Equal variances not assumed & & & 2.31 & 12.71 & 0.058 & 118.73 & 51.39 & 7.45 & 230 \\
\hline \multirow{2}{*}{ TN } & Equal variances assumed & \multirow{2}{*}{0.453} & \multirow{2}{*}{0.512} & 2.084 & 14 & 0.056 & 105.2 & 50.48 & -3.07 & 213.47 \\
\hline & Equal variances not assumed & & & 2.084 & 13.79 & 0.056 & 105.2 & 50.48 & -3.22 & 213.62 \\
\hline \multirow{2}{*}{ TP } & Equal variances assumed & \multirow{2}{*}{0.008} & \multirow{2}{*}{0.932} & 0.713 & 14 & 0.487 & 2.85 & 4 & -5.72 & 11.42 \\
\hline & Equal variances not assumed & & & 0.713 & 13.91 & 0.488 & 2.85 & 4 & -5.73 & 11.43 \\
\hline \multirow{2}{*}{$\mathrm{NO}_{3}-\mathrm{N}$} & Equal variances assumed & \multirow{2}{*}{13.856} & \multirow{2}{*}{0.002} & -1.183 & 14 & 0.257 & -20.13 & 17.02 & -56.62 & 16.37 \\
\hline & Equal variances not assumed & & & -1.183 & 9.63 & 0.265 & -20.13 & 17.02 & -58.24 & 17.99 \\
\hline \multirow{2}{*}{$\mathrm{PO}_{4}-\mathrm{P}$} & Equal variances assumed & \multirow{2}{*}{3.203} & \multirow{2}{*}{0.095} & -0.561 & 14 & 0.583 & -0.61 & 1.09 & -2.95 & 1.73 \\
\hline & Equal variances not assumed & & & -0.561 & 7.36 & 0.591 & -0.61 & 1.09 & -3.17 & 1.94 \\
\hline & \multirow[b]{2}{*}{ Anoxic } & \multicolumn{4}{|c|}{ Levene's Test for Equality of Variances } & \multicolumn{5}{|c|}{$t$-Test for Equality of Means } \\
\hline & & $\mathbf{F}$ & Sig. & $\mathbf{t}$ & df & Sig. & $\begin{array}{c}\text { Mean } \\
\text { Difference }\end{array}$ & Std. Error & $\begin{array}{r}95 \% \text { Confic } \\
\text { the I }\end{array}$ & $\begin{array}{l}\text { Interval of } \\
\text { nce }\end{array}$ \\
\hline & Equal variances assumed & & & 4.015 & 14 & 0.001 & 192.09 & 47.85 & 89.47 & 294.71 \\
\hline COD & Equal variances not assumed & 1.036 & 0.326 & 4.015 & 11.94 & 0.002 & 192.09 & 47.85 & 87.78 & 296.39 \\
\hline & Equal variances assumed & & & 2.728 & 14 & 0.016 & 228.34 & 83.7 & 48.82 & 407.85 \\
\hline TN & Equal variances not assumed & 9.62 & 0.008 & 2.728 & 8.32 & 0.025 & 228.34 & 83.7 & 36.62 & 420.05 \\
\hline TP & Equal variances assumed & & & 2.244 & 14 & 0.042 & 18.95 & 8.44 & 0.84 & 37.06 \\
\hline 10 & Equal variances not assumed & 1.64 & 0.221 & 2.244 & 11.53 & 0.045 & 18.95 & 8.44 & 0.47 & 37.43 \\
\hline & Equal variances assumed & & & -0.219 & 14 & 0.83 & -1.08 & 4.9 & -11.58 & 9.43 \\
\hline $\mathrm{NO}_{3}-\mathrm{N}$ & Equal variances not assumed & 0.447 & 0.515 & -0.219 & 13.99 & 0.83 & -1.08 & 4.9 & -11.59 & 9.44 \\
\hline & Equal variances assumed & & & 2.041 & 14 & 0.061 & 5.1 & 2.5 & -0.26 & 10.46 \\
\hline $\mathrm{PO}_{4}-\mathrm{P}$ & Equal variances not assumed & 7.39 & 0.017 & 2.041 & 9.42 & 0.07 & 5.1 & 2.5 & -0.52 & 10.72 \\
\hline
\end{tabular}

Note: Division of pollution source types: Group A (livestock pollution: reservoir Y and G). Group B (sewage pollution: reservoir I and E). 
Accordingly, sufficient aeration is required when the bottom of the reservoir becomes anoxic. For old reservoirs subject to livestock pollution sources in particular, priority must be given to sediment management. Additionally, it is necessary to control and manage the release of contaminants from sediments by supplying oxygen to the bottom water of reservoirs during every season.

\subsection{Comparison of Pollutant Loads and Release Fluxes in the Study Area}

The correlation characteristics for the pollutant loads and release of organic matter and nutrients from sediments in the studied reservoirs were analyzed and compared. The average daily release fluxes $(\mathrm{kg} /$ day) were calculated using the total area occupied by the water and the release rate estimated from the release experiments. Data of the pollutant loads was obtained from agricultural-water-monitoring reports [26]. This information is summarized in Table 8.

Table 8. Summary of release fluxes from sediments and pollutant loads at the study sites.

\begin{tabular}{|c|c|c|c|c|c|c|c|c|c|c|}
\hline & \multicolumn{3}{|c|}{ Pollutant Loads (kg/Day) } & \multirow{2}{*}{ Condition } & \multicolumn{6}{|c|}{ Release Fluxes (kg/Day) } \\
\hline & COD & TN & $\mathbf{T P}$ & & COD & TN & TP & $\mathrm{NH}_{4}-\mathrm{N}$ & $\mathrm{NO}_{3}-\mathrm{N}$ & $\mathrm{PO}_{4}-\mathrm{P}$ \\
\hline \multirow{3}{*}{ COD } & \multirow{3}{*}{248.0} & \multirow{3}{*}{122.7} & \multirow{3}{*}{22.3} & Control & 1.6 & 6.5 & 4.4 & 3.2 & - & 0.5 \\
\hline & & & & Oxic & 6.7 & 14.7 & - & - & 5.6 & - \\
\hline & & & & Anoxic & 61.8 & 53.6 & 7.5 & 9.1 & - & 5.5 \\
\hline \multirow{3}{*}{ TN } & \multirow{3}{*}{223.3} & \multirow{3}{*}{119.6} & \multirow{3}{*}{21.6} & Control & 4.9 & 3.0 & - & 6.1 & - & - \\
\hline & & & & Oxic & 8.6 & 1.7 & - & - & 7.1 & - \\
\hline & & & & Anoxic & 57.0 & 48.8 & 9.8 & 11.4 & - & 4.1 \\
\hline \multirow{3}{*}{ TP } & \multirow{3}{*}{122.2} & \multirow{3}{*}{78.2} & \multirow{3}{*}{20.5} & Control & - & - & 0.1 & 6.7 & - & 0.6 \\
\hline & & & & Oxic & - & - & - & - & 22.6 & 0.1 \\
\hline & & & & Anoxic & 59.3 & 1.8 & 9.9 & 19.2 & - & 9.8 \\
\hline \multirow{3}{*}{$\mathrm{NH}_{4}-\mathrm{N}$} & \multirow{3}{*}{131.1} & \multirow{3}{*}{61.9} & \multirow{3}{*}{22.5} & Control & - & 0.1 & 0.3 & 5.5 & 1.5 & 1.1 \\
\hline & & & & Oxic & - & - & - & - & 16.6 & - \\
\hline & & & & Anoxic & 7.6 & 2.0 & 5.6 & 11.6 & - & 4.7 \\
\hline
\end{tabular}

The results showed that the release fluxes of organic matter and nutrients differed according to the pollution source, year of construction, and experimental environmental conditions (control, oxic, or anoxic) at the study sites. If the concentrations of nitrogen or phosphorus in sediment pore water were lower than that in the upper water layer, negative results were obtained when the nutrients migrated from the upper water layer into the pore water because of the difference in concentrations. Additionally, a negative result was noted even when the nitrogen and phosphorus concentrations increased because of microbial activity in the sediments. Therefore, the calculation of the release fluxes yielded only positive results, which could affect the contamination of the reservoir water. The daily average release fluxes were COD $=1.6-61.8 \mathrm{~kg} /$ day, $\mathrm{TN}=0.1-53.6 \mathrm{~kg} /$ day, $\mathrm{TP}=0.1-9.9 \mathrm{~kg} /$ day, $\mathrm{NH}_{4}-\mathrm{N}=3.2-19.2 \mathrm{~kg} /$ day, $\mathrm{NO}_{3}-\mathrm{N}=1.5-22.6 \mathrm{~kg} /$ day, and $\mathrm{PO}_{4}-\mathrm{P}=0.1-9.8 \mathrm{~kg} /$ day.

We also compared the influent pollutant loads to each reservoir (Table 8 ) and the release fluxes of organic matter and nutrients under anoxic conditions, which were expected to have the greatest polluting effect because of their release from sediments. Comparing the TN and TP release fluxes with the influent pollutant loads yielded values of $43.7 \%$ and $33.8 \%$ for reservoir Y, $40.8 \%$ and $45.2 \%$ for reservoir G, $2.3 \%$ and $48.1 \%$ for reservoir I, and $3.3 \%$ and $24.9 \%$ for reservoir E, respectively. Therefore, the water quality of reservoirs $Y$ and $G$ (which experienced agricultural livestock pollution) could be affected to a great extent because of TN and TP release from bottom reservoir sediments under anoxic conditions. On the other hand, TN in reservoirs I and E (which experienced pollutant loads from sewage sources) was estimated to have little effect on reservoir water quality under anoxic conditions. However, TP could have a considerable effect on the water quality, and the pollution level could worsen.

In situ testing for the study was conducted while maintaining DO levels and water temperatures similar to the field conditions. However, physicochemical environmental changes that occur because 
of actual rainfall runoff, inflow and outflow of water, and biological environment changes from microbial activity could not be reflected accurately within the given experimental time frame. However, several other studies have obtained significant results by using the same experimental procedure, as that used for the release experiment in the current study [32,36-38]. Several other studies have also yielded meaningful results. Therefore, we are fairly confident that our results can be considered as representative for this study's time frame.

\section{Conclusions}

This study investigated the effects of sediment release on water quality and pollution in four agricultural reservoirs in South Korea. The study analyzed the sediment release characteristics according to the year the reservoir was constructed in and its sources pollutant loads. The reservoir water quality was investigated under the following conditions depending on when the experiments were conducted: $\mathrm{DO}$ of $1.3-10.8 \mathrm{mg} / \mathrm{L}$, water temperature of $4.0-29.8{ }^{\circ} \mathrm{C}$, and $\mathrm{pH}$ of $5.8-9.3$. We confirmed that the bottom water below a depth of $5 \mathrm{~m}$ in a reservoir could be anoxic. The results of the analysis of sediment characteristics showed that the fraction of fine particles (below $63 \mu \mathrm{m}$ ) in all the study sites was higher than $70 \%$. In the old reservoirs ( $\mathrm{Y}$ and I), the contamination degree in terms of LOI, TN, and TP was high.

Furthermore, sediments collected in the field were used for release experiments under oxic, anoxic, and control conditions by employing the sediment core culture method. The release concentration of $\mathrm{NO}_{3}-\mathrm{N}$ increased under oxic conditions for all the study sites and the concentrations of $\mathrm{NH}_{4}-\mathrm{N}, \mathrm{TP}$, and $\mathrm{PO}_{4}-\mathrm{P}$ increased under anoxic conditions. The control group showed differences in the release concentration depending on the target region and analysis factors. This result could be attributed to variations in the material exchange process between the sediments and water column in accordance with environmental changes.

The characteristics of the release rates relevant to the construction year and according to each pollution source were determined for the study sites. The release rates for each pollution source were found to be high in the old reservoirs. In particular, except for TN in the reservoirs experiencing loading from sewage sources, the release rates were positive under anoxic conditions; this was particularly pronounced for $\mathrm{COD}, \mathrm{TN}, \mathrm{TP}, \mathrm{NH}_{4}-\mathrm{N}$, and $\mathrm{PO}_{4}-\mathrm{P}$. However, $\mathrm{NO}_{3}-\mathrm{N}$ showed a positive release rate under oxic conditions, and it was higher irrespective of the pollution source in the older reservoirs.

The release rates of COD, TN, and TP under anoxic conditions were higher in the reservoirs experiencing pollution from livestock compared with those experiencing pollutant loading from sewage sources. However, $\mathrm{NO}_{3}-\mathrm{N}$ showed a higher release rate in the latter under oxic conditions. This result can be ascribed to the denitrification effect of nitrite and nitrate, and to biological activity in the sediments.

Consequently, effective aeration technology is required to aerate the reservoir bottom water when conditions become anoxic. It is particularly important to manage the sediments of old reservoirs that experience livestock pollution, and to control and manage the release of pollutants from them by supplying oxygen to the reservoir bottom water during each season.

The sediment release characteristics of organic matter and nutrients were compared and analyzed to determine the relationship between sediment release and influent pollutant loads for the study sites. The release fluxes (internal sources) of TN and TP for the influent pollutant loads (external sources) were $2.3-43.7 \%$ and $24.9-48.1 \%$ for each reservoir, respectively. It was estimated that the sediment release of TN in reservoirs I and $\mathrm{E}$ (which experienced pollutant loads from sewage sources) hardly influenced the water quality under anoxic conditions. However, the sediment release of TP could have a significant effect, worsening water pollution. Additionally, TN and TP in reservoirs $Y$ and G (which experienced livestock pollutant loads) were considered to have a considerable influence on water quality when anoxic conditions formed at the bottom of the reservoirs. Sediment release could thus worsen water pollution as an internal pollutant source. The sediment release fluxes were considerable compared with the influent pollutant loads, that is, the pollutants flowing into the reservoirs. Therefore, 
efforts to reduce the internal pollutant loads should continue. As the influent pollutant loads to agricultural reservoirs in South Korea vary, it is important to avoid a generalization of the results of this study on the influence of sediment release on water quality. However, water pollution caused by sediment release (i.e., an internal pollutant source) is not negligible; therefore, it is necessary to apply appropriate technologies to alleviate such pollution and to implement policies for appropriate management of reservoir sediments. As pollution control and management technologies must be applied in accordance with the sediment characteristics of each reservoir, these characteristics should be investigated carefully and monitored continuously.

Author Contributions: J.-K.L. developed the methodology, obtained and analyzed the data, and wrote the original draft. J.-M.O. contributed to development of the ideas, interpretation of results, and manuscript review.

Acknowledgments: We would like to thank Korea Rural Community Corporation (KRC) and Rural Research Institute (RRI) for providing some data.

Conflicts of Interest: The authors declare no conflict of interest.

\section{References}

1. Frenchel, T.; King, G.M.; Blackburn, T.H. Bacterial Biogeochemistry: The Ecophysiology of Mineral Cycling, 3rd ed.; Academic Press: San Diego, CA, USA, 2012; pp. 303-305, ISBN 9780124158368.

2. MacDonald, D.D.; Ingersoll, C.G.; Berger, T.A. Development and evaluation of consensus-based sediment quality guidelines for freshwater ecosystems. Arch. Environ. Contam. Toxicol. 2000, 39, 20-31. [CrossRef] [PubMed]

3. Ingersoll, C.G.; Dillon, T.; Biddinger, G.R. Ecological risk assessments of contaminated sediment. In Proceedings of the Pellston Workshop on Sediment Ecological Risk Assessment, Pacific Grove, CA, USA, 23-28 April 1995; SETAC Press: Brussels, Belgium, 1997; pp. 70-71.

4. Sawyer, C.N.; McCarty, P.L.; Parkin, G.F. Chemistry for Environmental Engineering and Science, 5th ed.; McGraw Hill: New York, NY, USA, 2002; pp. 123-125, ISBN 9780072480665.

5. Alonso-Pērez, F.; Castre, C.G. Benthic oxygen and nutrient fluxes in a coastal upwelling system (Ria de Vigo, NW Iberian Peninsula): Seasonal trends and regulating factors. Mar. Ecol. Prog. Ser. 2014, 511, 17-32. [CrossRef]

6. Theofanis, Z.U.; Astrid, S.; Lidia, G.; Calmamo, W. Contaminants in sediments-remobilisation and demobilization. Sci. Total Environ. 2001, 266, 195-202. [CrossRef]

7. Esten, M.E.; Wagner, K.J. Investigation of benthic phosphorus flux controls in Lake Waco, Texas. Lake Reserv. Manag. 2010, 26, 114-122. [CrossRef]

8. Ancey, C.; Böhm, T.; Jodeau, M.; Frey, P. Statistical description of sediment transport experiments. Phys. Rev. 2006, 74, 011302. [CrossRef] [PubMed]

9. Bomminayuni, S.; Stoesser, T. Turbulence statistics in an open-channel flow over a rough bed. J. Hydraul. Eng. 2011, 137, 1347-1358. [CrossRef]

10. Detert, M.; Nikora, V.; Jirka, G.H. Synoptic velocity and pressure fields at the water-sediment interface of streambeds. J. Fluid Mech. 2010, 660, 55-86. [CrossRef]

11. Sothwell, M.W.; Mead, R.N.; Luquire, C.M.; Barbera, A.; Avery, G.B.; Kieber, R.J.; Skrabal, S.A. Influence of organic matter source and diagenetic state on photochemical release of dissolved organic matter and nutrients from resuspendable estuarine sediments. Mar. Chem. 2011, 126, 114-119. [CrossRef]

12. Cheng, X.; Zeng, Y.; Guo, Z.; Zhu, L. Diffusion of nitrogen and phosphorus across the sediment-water interface and in seawater at aquaculture areas of Daya Bay. China Int. J. Environ. Res. Public Health 2014, 11, 1557-1572. [CrossRef] [PubMed]

13. Nowlin, W.H.; Evarts, J.L.; Vanni, M.J. Release rates and potential fates of nitrogen and phosphorus from sediments in a eutrophic reservoir. Freshw. Biol. 2005, 50, 301-322. [CrossRef]

14. Søndergaard, M.; Jensen, J.P.; Jeppesen, E. Role of sediment and internal loading of phosphorus in shallow lakes. Hydrobiologia 2003, 506, 135-145. [CrossRef]

15. Fisher, M.M.; Reddy, K.R.; Thomas, J.R. Internal nutrient loads from sediments in shallow, subtropical lake. Lake Reserv. Manag. 2005, 21, 338-349. [CrossRef] 
16. Søndergaard, M.; Jensen, J.P.; Jeppesen, E. Internal phosphorus loading in shallow Danish lakes. Hydrobiologia 1999, 408/409, 145-152. [CrossRef]

17. Malecki, L.M.; White, J.R.; Reddy, K.R. Nitrogen and phosphorus flux rates from sediment in the lower St. Johns River estuary. J. Environ. Qual. 2004, 33, 1545-1555. [CrossRef] [PubMed]

18. Glud, R.N. Oxygen dynamics of marine sediments. Mar. Biol. Res. 2008, 4, 243-289. [CrossRef]

19. Kristensen, E.; Holmer, M. Decomposition of plant materials in marine sediment exposed to different electron acceptors $\left(\mathrm{O}_{2}, \mathrm{NO}_{3}{ }^{-}\right.$, and $\left.\mathrm{SO}_{4}{ }^{2-}\right)$, with emphasis on substrate origin, degradation kinetics, and the role of bioturbation. Geochim. Cosmochim. Acta 2001, 65, 419-433. [CrossRef]

20. Miller, J.R.; Sinclair, J.T.; Walsh, D. Controls on suspended sediment concentrations and turbidity within a reforested, Southern Appalachian headwater basin. Water 2015, 7, 3123-3148. [CrossRef]

21. Percuoco, V.P.; Kalnejais, L.H.; Officer, L.V. Nutrient release from the sediments of the Great Bay Estuary, N.H. USA. Estuar. Coast. Shelf Sci. 2015, 161, 76-87. [CrossRef]

22. Cheng, X.; Zhu, D.; Wang, X.; Yu, D.; Xie, J. Effects of nonaerated circulation water velocity on nutrient release from aquaculture pond sediments. Water 2017, 9, 6. [CrossRef]

23. Sahuquillo, A.; Rigol, A.; Rauret, G. Overview of the use of leaching/extraction tests for risk assessment of trace metals in contaminated soils and sediments. Trends Anal. Chem. 2003, 22, 152-159. [CrossRef]

24. McComas, S. Lake and Pond Management; LEWIS: Boca Raton, FL, USA, 2003; p. 286, ISBN 1566706300.

25. Ministry of Agriculture, Food and Rural Affairs (MAFRA). Development of Sediment Management Technology for Agricultural Reservoirs; MAFRA: Guelph, ON, Canada, 2015; pp. 3-9.

26. Korea Rural Community Corporation (KRC). Agricultural Water Monitoring Reports; KRC: Jeollanam-do, Korea, 2015; pp. 23-59.

27. Rural Water Information System (RAWRIS). Available online: https://rawris.ekr.or.kr (accessed on 5 September 2016).

28. National Institute of Agricultural Science and Technology (NIAST). Analysis Methods for Soils and Plants; NIAST: Jeollabuk-do, Korea, 2000; pp. 35-57.

29. American Public Health Association (APHA). Standard Methods for the Examination of Water and Wastewater, 22nd ed.; APHA/American Water Works Association/Water Environment Federation: Washington, DC, USA, 2012.

30. United States Department of Agriculture (USDA). Soil Science Division Staff. Soil Survey Manual: USDA Textural Classification. Available online: https: / www.nrcs.usda.gov / wps (accessed on 25 June 2016).

31. Selig, U. Particle size-related phosphate binding and P-release at the sediment-water interface in a shallow German lake. Hydrobiologia 2003, 492, 107-118. [CrossRef]

32. Hammond, D.E.; Cummins, K.M.; McManus, J.; Berelson, W.M.; Smith, G.; Spagnoli, F. Methods for measuring benthic nutrient flux on the California Margin: Comparing shipboard core incubation to in situ lander results. Limnol. Oceanogr. Methods 2004, 2, 146-159. [CrossRef]

33. Oh, H.S.; Shin, W.S.; Kim, J.H.; Hwang, I.S.; Hur, J.; Shin, H.S.; Oh, J.E.; Huh, I.; Kim, Y.H. Comparison of particle size analysis and distribution of heavy metals in river and lake sediments. J. Korea Geo-Environ. Soc. 2010, 11, 15-23. [CrossRef]

34. Oh, H.S.; Huh, I.A.; Chi, J.H. Laboratory study of phosphorus fractionation in the sediments of Yeongsan River. J. Korean Soc. Environ. Eng. 2017, 39, 519-526. [CrossRef]

35. Jensen, H.S.; Andersen, F. Importance of temperature, nitrate and $\mathrm{pH}$ for phosphate release from aerobic sediments of four shallow, eutrophic lakes. Limnol. Oceanogr. 1992, 37, 577-589. [CrossRef]

36. Kim, T.H.; Kang, J.K.; Kim, S.H.; Choi, I.S.; Chang, K.H.; Oh, J.M.; Kim, K.H. Impact of Salinity Change on Water Quality Variables from the Sediment of an Artificial Lake under Anaerobic Conditions. Sustainability 2017, 9, 1429. [CrossRef]

37. Environmental drivers of benthic flux variation and ecosystem functioning in Salish Sea and northeast Pacific sediments. PLoS ONE 2016, 11, e0151110. [CrossRef]

38. Aller, R.A.; Blair, N.E.; Xia, Q.; Rude, P.D. Remineralization rates, recycling, and storage of carbon in Amazon shelf sediments. Cont. Shelf Res. 1996, 16, 753-789. [CrossRef]

(C) 2018 by the authors. Licensee MDPI, Basel, Switzerland. This article is an open access article distributed under the terms and conditions of the Creative Commons Attribution (CC BY) license (http:/ / creativecommons.org/licenses/by/4.0/). 